\title{
Infective Exacerbations of Chronic Obstructive Pulmonary Disease with or without Pneumonia
}

\author{
Sami Deniz ${ }^{1}$, Mustafa Hikmet Özhan² \\ ${ }^{1}$ Clinic of Chest Diseases, Didim State Hospital, Aydın \\ ${ }^{2}$ Department of Chest Disease, Ege University Faculty of Medicine, İzmir
}

\begin{abstract}
Objective: It was aimed to evaluate the relation between the presence of pneumonia and clinical, demographic and biochemical data of patients with a diagnosis of Chronic Obstructive Pulmonary Disease (COPD) during exacerbation in case-control groups.

Methods: The present study, which was designed as a prospective study, included COPD cases with or without pneumonia diagnosis, hospitalized between 2007 and 2008 in a tertiary chest diseases clinic for acute exacerbation. Patients that were diagnosed with pneumonia based on clinical and radiological findings at the time of hospitalization were assigned to the pneumonic exacerbation (PE) group and the cases without significant infiltration were assigned to the non-pneumonic exacerbation ( $\mathrm{n}-\mathrm{PE}$ ) group. All patients were investigated in terms of demographic and biochemical data, as well as pulmonary function tests and time to exacerbation. Data were compared using chi-square test for categorical variables and student $t$-test for parametric variables, and a $\mathrm{p}<0.05$ was considered significant. Relation between variables was analysed by Pearson correlation test.
\end{abstract}

Results: The study included 30 patients ( 23 males and 7 females; mean age \pm SD:69 \pm years) with signs of exacerbation without pneumonia and 30 COPD patients ( 23 males and 7 females; mean age \pm SD:69 \pm 9 years) with a diagnosis of pneumonia. No difference was determined between the groups in terms of age, gender, presence of diabetes, number of annual exacerbations, and previous antibiotic use. The amount of cigarette smoking $(59 \pm 36$ pack.year versus $38 \pm 37$ pack.year; $p<0.05)$ was higher and disease duration (COPD) $(15 \pm 11$ years versus $7.7 \pm 8$ years; $p<0.05$ ) was longer in the exacerbation group without pneumonia. Among laboratory findings, whilst there was no difference between the groups in terms of C-reactive protein (CRP), lactate dehydrogenase (LDH) and leukocyte counts, it was observed that forced expiratory volume in 1 second $\left(\mathrm{FEV}_{1}\right)(33.5 \pm 10 \%$ versus $55 \pm 19 \%$; $\mathrm{p}<0.05)$ was lower in the exacerbation group without pneumonia.

Conclusion: It is concluded that COPD patients who were more serious cigarette addicts, had a lower forced expiratory volume in 1 second $\left(\mathrm{FEV}_{1}\right)$ and a longer disease duration are more prone to exacerbations without pneumonia.

Keywords: COPD exacerbation, pneumonia, duration of smoking, duration of COPD, FEV

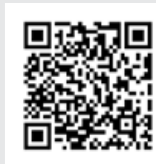

Received date: 27.11 .2012

Accepted date: 15.03 .2013

Address for correspondence

Sami Deniz, Clinic of Chest Diseases, Didim State Hospital, Aydın, Turkey

E-mail: sami_deniz@yahoo.com

(C) Copyright 2014 Turkish Respiratory Society (TRS) DOI: $10.5152 /$ ejp.2014.59219

-Available online at www.eurasianjpulmonol.com

\section{INTRODUCTION}

Chronic obstructive pulmonary disease (COPD), which is defined as a common preventable and treatable disease, is characterized by generally progressive persistent airflow limitation associated with an intense chronic inflammatory response against harmful particles or gases in the airways and lungs (1). Chronic obstructive pulmonary disease is one of the leading causes of morbidity and mortality all over the world and it has become an increasing socioeconomic burden (2). In the European Union, respiratory diseases account for $6 \%$ of overall health budget, of which $56 \%$ has been reported to be COPD-related cost (3). In the United States of America, the direct cost of COPD is estimated to be 29.5 billion dollars, whereas the indirect cost is estimated to be 20.4 billion dollars. COPD exacerbations account for the great majority of overall chronic obstructive pulmonary disease-related burden and costs increase as the stage of disease increases (4). 
It is known that exacerbations of chronic obstructive pulmonary disease accelerate the annual reduction in pulmonary functions (5). Low $\mathrm{FEV}_{1}$ is one of the important risk factors in COPD exacerbations. COPD exacerbation accelerates the decrease in $\mathrm{FEV}_{1}$. In addition to infections, exposure to air pollution and harmful particles may also cause exacerbations. The cause of exacerbation cannot be determined in one third of the cases (6). Although there are several causes of COPD exacerbations, it is assumed that the most common causes are viral or bacterial respiratory tract infections. In bronchoscopy studies, bacteria were detected in the lower airways during COPD exacerbations in half of the patients (7). Even though this bacterial colonization is seen in the stable phase of the disease, it is thought that newly acquired bacterial strains may cause COPD exacerbation (8). Whatever the reason is COPD exacerbations, particularly those having indication for hospitalization, are associated with high mortality and have a high socio-economic cost (9).

When patients with COPD develop pneumonia, CRP level is elevated due to inflammation. Furthermore, increased CRP levels and statistically significant decrease after treatment was determined in almost all cases, in which bacterial pathogens have been isolated during COPD exacerbation (10).

The effect of bacterial burden and pneumonia on the severity of COPD exacerbations, as well as predisposing factors for pneumonia and clinical and biochemical differences, has not been largely investigated. In the present study, the demographic, clinical and laboratory characteristics of COPD exacerbations with and without pneumonia were evaluated and compared.

\section{METHODS}

The present study included 60 patients ( 46 males and 14 females) with a mean age \pm SD of $69 \pm 9$ years who had been previously diagnosed with COPD and hospitalized between 2007 and 2008 in a tertiary chest diseases clinic for acute exacerbation. Patients diagnosed according to the Global Initiative for Chronic Obstructive Lung Disease (GOLD) diagnostic criteria and that have been followed up for COPD for at least 5 years were selected. Patients were evaluated on the day of hospital stay. The study was approved by the Ethics committee and consents of the patients were obtained. The diagnosis of infective COPD exacerbations was based not only on daily changes such as increase in the amount and purulence of sputum and increase in dyspnoea, but also acute impairment of respiratory symptoms to the extent that might lead to changes in treatment (1). Cases with additional pulmonary diseases (lung cancer, pulmonary fibrosis) other than chronic obstructive pulmonary disease that may influence disease course were excluded from the study. Patients that have been diagnosed with pneumonia based on clinical and radiological findings (localized rales, bronchial breath sounds and new consolidation areas) at the time of hospitalization were assigned to the pneumonic exacerbation group (PE), and the patients without a significant infiltration were assigned to the non-pneumonic exacerbation group ( $\mathrm{n}-\mathrm{PE}$ ). All patients were investigated in terms of demographic and biochemical data as well as pulmonary function tests and duration of exacerbation.

\section{Statistical Analysis}

Study data were transferred to the database that was formed on Statistical Package for Social Sciences (SPSS) 15.0 program and statistical analysis was performed using the same program. Whilst "Chi-Square test" was used for categorical variables, "Student's t-test" was used for parametric measurements. A p value $<0.05$ was considered to be statistically significant. The relation between variables was analysed by Pearson correlation test.

\section{RESULTS}

Of the 60 COPD patients that were hospitalized for acute exacerbation and included in the study, 30 (23 males and 7 females; mean age \pm SD: $67 \pm 9$ years) were assigned to the $n-P E$ group, whereas the other 30 patients ( 23 males and 7 females; mean age \pm SD: $69 \pm 9$ years) were assigned to the PE group. No statistically significant difference was determined between the groups in terms of demographic variables including age, gender, and presence of diabetes as a concomitant disease. Number of annual exacerbations was $2.5 \pm 2.4$ exacerbation/ year in the $n-P E$ group and $2.7 \pm 2.6$ exacerbation/year in the PE group. There was no difference between the groups in terms of antibiotherapy received during the previous exacerbation. The duration of COPD was $15 \pm 11$ years in the $n-P E$ group and $7.7 \pm 8$ in the $P E$ group $(p<0.05)$. The intensity of cigarette smoking (pack.year) was found higher in the n-PE group as compared to the PE group (59.4 \pm 36 and $38.2 \pm 37$ respectively, $\mathrm{p}<0.05)$. Table 1 illustrates the demographic characteristics of the groups.

In terms of biochemical variables, CRP and leukocyte count were mildly higher in the PE group with no significant difference between the groups ( $13.5 \pm 12.3$ and $14.213 \pm 7501$ respectively, in the PE group; $6.1 \pm 7.5$, and $11.906 \pm 5309.0$ respectively, in the $n$-PE group) (the suitability of continuous variables to normal distribution was not tested). $\mathrm{FEV}_{1}$ values were significantly lower in the n-PE group as compared to the PE group ( $33.5 \pm 10.3 \%$ and $54.9 \pm 19.5$, respectively) (Table 2 ).

Table 1. Comparison of demographic characteristics of cases

\begin{tabular}{|c|c|c|c|}
\hline & n-PE (30) & PE (30) & $\mathbf{p}$ \\
\hline Age (mean $\pm S D$ ) years & $67.8 \pm 9.2$ & $69.9 \pm 9.0$ & $>0.05$ \\
\hline Male gender $\mathrm{n}(\%)$ & $23(76.7 \%)$ & $23(76.7 \%)$ & \\
\hline Diabetes mellitus n (\%) & $7(58.3 \%)$ & $5(41.7 \%)$ & $>0.05$ \\
\hline Number of exacerbations (n/year) & $2.5 \pm 2.4$ & $2.7 \pm 2.6$ & $>0.05$ \\
\hline Antibiotic use $\mathrm{n}(\%)$ & & & $>0.05$ \\
\hline Ampicillin-sulbactam & $1(3.3 \%)$ & 0 & \\
\hline Amoxicillin - CA & $4(13.3 \%)$ & $6(20.0 \%)$ & \\
\hline Respiratory quinolone & $10(33.3 \%)$ & $10(33.3 \%)$ & \\
\hline Macrolide & $4(13.3 \%)$ & $1(3.3 \%)$ & \\
\hline $2^{\text {nd }}$ generation cephalosporin & $6(20.0 \%)$ & $3(10.0 \%)$ & \\
\hline $3^{\text {rd }}$ generation cephalosporin & $1(3.3 \%)$ & $1(3.3 \%)$ & \\
\hline Meropenem & $1(3.3 \%)$ & $1(3.3 \%)$ & \\
\hline Piperacillin-Taz & 0 & $1(3.3 \%)$ & \\
\hline Ciprofloxacin & $2(6.7 \%)$ & $1(3.3 \%)$ & \\
\hline Not used & $1(3.3 \%)$ & $6(20.0 \%)$ & \\
\hline Disease duration (years) (mean $\pm S D)$ & $15.0 \pm 11.0$ & $7.7 \pm 8.0$ & $<0.05$ \\
\hline Smoking (pack.year) (mean \pm SD) & $59.4 \pm 36.8$ & $38.2 \pm 37.4$ & $<0.05$ \\
\hline
\end{tabular}


Comparing those with and without diabetes in the pneumonic and n-PE groups using Student's t-test in terms of laboratory results, FEV and number of exacerbations, only CRP was found to be significantly higher in the presence of diabetes in the PE group (26.7 \pm 14.9$)$ as compared to the $n-P E$ group $(3.3 \pm 2.5)(p<0.05)$ (Table 3).

Table 2. Comparison of laboratory parameters and FEV $(\%)$ between groups

\begin{tabular}{|l|c|c|c|}
\hline Laboratory parameters & $\begin{array}{c}\mathrm{n}-\mathrm{PE} \\
\text { (mean } \pm \text { SD) }\end{array}$ & $\begin{array}{c}\mathrm{PE} \\
\text { (mean } \pm \text { SD) }\end{array}$ & $\begin{array}{c}\mathbf{p} \\
\text { value }\end{array}$ \\
\hline $\mathrm{CRP}(\mathrm{mg} / \mathrm{dL})$ & $6.1 \pm 7.5$ & $13.5 \pm 12.3$ & 0.07 \\
$\mathrm{LDH}(\mathrm{U} / \mathrm{L})$ & $510.4 \pm 480.9$ & $379.5 \pm 110.0$ & 0.15 \\
Leukocyte $\left(/ \mathrm{mm}^{3}\right)$ & $11.906 \pm 5309.0$ & $14.213 \pm 7501.0$ & 0.16 \\
\hline FEV $\%$ & $33.5 \pm 10.3$ & $54.9 \pm 19.5$ & $<0.05$ \\
\hline
\end{tabular}

CRP: C-reactive protein; $\mathrm{FEV}_{1}$ : forced expiratory volume in 1 second; $\mathrm{LDH}$ : lactate dehydrogenase; $\mathrm{n}-\mathrm{PE}$ : non- pneumonic exacerbation; PE: pneumonic exacerbation; SD: standard deviation
Comparison of intragroup markers revealed a positive correlation between $\mathrm{FEV}_{1}$ and leukocyte count in the n-PE group and between leukocyte count and CRP in the PE group ( $p<0.05)$, whereas no correlation was determined between the other markers (Table 4).

\section{DISCUSSION}

In the present study, the evaluation of 60 patients who were hospitalized for COPD exacerbation revealed that disease duration was longer, FEV 1 was lower and history of smoking was higher in the $\mathrm{n}$-PE group compared to the PE group. As was expected, the levels of inflammatory markers were higher in the pneumonic exacerbation group, but probably due to the limited patient number, the difference did not reach a statistically significant level. The presence of diabetes significantly enhanced CRP levels in cases diagnosed with pneumonic exacerbation.

In the study conducted by Hurst et al. (11), whilst the annual number of exacerbations in the first year was 0.85 for patients with stage 2

Table 3. Comparison of laboratory parameters, number of exacerbations and FEV1 measurements between diabetic and non-diabetics in the groups

\begin{tabular}{|c|c|c|c|c|}
\hline & & $\mathrm{DM}($ mean $\pm \mathrm{SD})$ & Non-DM (mean \pm SD) & p \\
\hline & LDH (U/L) & $787.3 \pm 931.2$ & $426.2 \pm 190.9$ & \\
\hline & $\mathrm{CRP}(\mathrm{mg} / \mathrm{dL})$ & $3.3 \pm 2.5$ & $7.0 \pm 8.4$ & \\
\hline \multirow[t]{5}{*}{$n-P E(n=30)$ group } & Leukocyte $\left(/ \mathrm{mm}^{3}\right)$ & $12600.0 \pm 3481.0$ & $11674.6 \pm 5797.2$ & $>0.05$ \\
\hline & $\mathrm{FEV}_{1}(\%)$ & $27.2 \pm 10.8$ & $35.6 \pm 9.6$ & \\
\hline & Number of exacerbations ( $n$ ) & $2.7 \pm 2.0$ & $2.5 \pm 2.5$ & \\
\hline & LDH ( U/L) & $413.8 \pm 203.5$ & $372.7 \pm 86.1$ & $>0.05$ \\
\hline & CRP $(\mathrm{mg} / \mathrm{dL})$ & $26.7 \pm 14.9$ & $10.8 \pm 10.0$ & $<0.05$ \\
\hline \multirow[t]{3}{*}{$P E(n=30)$ group } & Leukocyte(/mm³) & $16358.0 \pm 6407.3$ & $13784.8 \pm 7745.7$ & $>0.05$ \\
\hline & $\mathrm{FEV}_{1}(\%)$ & $59.5 \pm 10.6$ & $54.4 \pm 20.5$ & $>0.05$ \\
\hline & Number of exacerbations ( $n$ ) & $3.0 \pm 2.1$ & $2.7 \pm 2.6$ & $>0.05$ \\
\hline
\end{tabular}

Table 4. Comparison of intragroup parameters within the groups

\begin{tabular}{|c|c|c|c|c|c|}
\hline n-PE group & LDH & CRP & Leukocyte & FEV1 & Exacerbation \\
\hline $\mathrm{LDH}$ & - & & & & \\
\hline CRP & $>0.05$ & - & & & \\
\hline Leukocyte & $>0.05$ & $>0.05$ & - & & \\
\hline $\mathrm{FEV}_{1}$ & $>0.05$ & $>0.05$ & $<0.05$ & - & \\
\hline Exacerbation & $>0.05$ & $>0.05$ & $>0.05$ & $>0.05$ & - \\
\hline PE group & LDH & CRP & Leukocyte & FEV1 & Exacerbation \\
\hline LDH & - & & & & \\
\hline CRP & $>0.05$ & - & & & \\
\hline Leukocyte & $>0.05$ & $<0.05$ & - & & \\
\hline $\mathrm{FEV}_{1}$ & $>0.05$ & $>0.05$ & $>0.05$ & - & \\
\hline Exacerbation & $>0.05$ & $>0.05$ & $>0.05$ & $>0.05$ & - \\
\hline
\end{tabular}


COPD, this rate was found to be 2 exacerbations per year for stage 4 COPD patients, and it was stated that stage 4 COPD patients had had two or more exacerbations in the following years. Frequency of exacerbations increases as the disease stage increases. In the present study, no significant difference was determined between the two groups in terms of number of exacerbations. It is thought that the number of exacerbations would reach a significant value in a larger patient population. Number of exacerbations due to infection and air pollution is expected to increase as airway obstruction increased as compared to the patients with a better $\mathrm{FEV}_{1}$ value. While air pollution increases the frequency of exacerbations in patients with COPD, it, on the other hand, leads to a decrease in $\mathrm{FEV}_{1}$ (12). Along with the decrease in FEV , which is the most important indicator of pulmonary functions, quality of life is impaired and prognosis of disease is worsened due to exacerbations (13).

Concomitant diseases are frequently encountered in COPD and they are substantially effective on prognosis. Prevalence of diabetes mellitus (DM), one of the concomitant diseases, is higher than that in the normal population even in stage 1 COPD patients, even though the underlying reason has not been understood yet (relative risk: 1.5-1.8) (14). In the present study, 12 (20\%) of 60 COPD patients had DM, of which 7 were in the $n-P E$ group and 5 were in the PE group. CRP level of patients with diabetes and pneumonia was higher as compared to the other groups. In COPD patients with diabetes, increased plasma CRP, TNF- $a$ and IL- 6 concentrations are also observed in metabolic syndrome, which involves also insulin resistance and cardiovascular disease (15). In the present study, the significant CRP elevation in DM patients as compared to non-DM patients in the PE group can be explained by not only the infection and systemic inflammation in stable COPD patients, but also by the contribution of DM to the chronic inflammation. CRP values in the stable phase of COPD would identify whether a CRP value of $3.3 \pm 2.5 \mathrm{mg} / \mathrm{dL}$ in the $\mathrm{n}-\mathrm{PE}$ group with diabetes is secondary to exacerbation or results from systemic inflammation. It has been demonstrated that presence of DM enhances prevalence of infections, exacerbations and mortality in patients with chronic obstructive pulmonary disease (16). It was determined that presence of diabetes facilitates the development of pneumonia and leads to significant CRP elevation, but this is not a common conclusion for all patients having DM and COPD exacerbation; otherwise, the same result would be expected for 7 COPD patients having diabetes and exacerbation without pneumonia. This difference could not be clarified because of the limited number of patients.

In the present study, a positive correlation was found between $\mathrm{FEV}_{1} \%$ and leukocyte count in the n-PE group and between leukocyte count and CRP in the PE group. In patients with advanced stage COPD, $\mathrm{FEV}_{1}$ decreases in proportion to increases in systemic inflammation. As systemic inflammation enhances, inflammatory markers increase significantly particularly during exacerbations, and this is associated with accelerated loss of lung capacity (17). Normally, there is a negative correlation between neutrophil count and $\mathrm{FEV}_{1}$ in cases with COPD; the severity of disease increases as neutrophil count increases (18). While a relatively milder increase in leukocyte count was detected with lower $\mathrm{FEV}_{1}$ in COPD patients with non-pneumonic exacerbation as compared to the PE group, a significant increase in leukocyte count was determined in the PE group, which had a higher $\mathrm{FEV}_{1} \%$. This can be explained by the tendency of more severe COPD patients to viral infections, having non-pneumonic exacerbations because of being more susceptible against air pollution, and indefinite response of leukocyte count as compared to the PE group.

As two inflammatory markers, increase in leukocyte count and CRP secondary to pneumonia is an expected finding. A case-control study including 43 COPD patients failed to demonstrate the relation between CRP, as an inflammatory marker, and severity of COPD (19). However, the relation of CRP and certain inflammatory markers with severity of COPD was demonstrated in a study including a large patient population (20). Man et al. (21) evaluated a large patient population and concluded that CRP gives information about prognosis and is associated with mortality. In the present study, serum CRP concentration was higher in the PE group but lower in the non-pneumonic COPD exacerbation group despite they had longer and more severe disease; however, no statistically significant difference was determined between the groups. CRP concentrations in the pneumonic COPD exacerbation group may be completely attributed to pneumonia. In a similar study, Lieberman et al. (22) defined a more severe disease in the PE group versus n-PE group in terms of clinical and laboratory parameters. In addition, it was stated that CRP elevation might not always be an indicator of bacterial infection even though it is a significant marker in COPD exacerbations (23).

In the present study, the duration of COPD was found to be shorter in the pneumonia group as compared to the n-PE group. It was determined that, probability of having a non-pneumonic exacerbation is higher in advanced stages but probability of having a pneumonic exacerbation is higher in the early stages of disease in COPD patients. It was thought that, a more definite conclusion could be reached with a larger patient population, in which demographic variables such as duration and stage of chronic obstructive pulmonary disease are homogeneous.

Not evaluating the patients in terms of previous inhaler therapy before exacerbation is one of the limitations of the present study; however, considering that $\mathrm{FEV}_{1} \%$ was $33.5 \pm 10.3$ in the $\mathrm{n}-\mathrm{PE}$ group and $54.9 \pm 19.5$ in the PE group and the patients had received treatment in accordance with GOLD criteria, the probability of receiving inhaled corticosteroid (ICS) treatment is higher in the group with

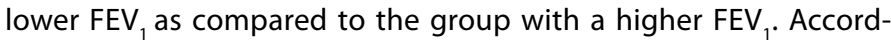
ingly, despite the higher use of ICS in the n-PE group, the diagnosis of pneumonic exacerbation shows negative correlation. Studies on the relation between inhaled corticosteroid use and pneumonia yielded diverse results. Although the risk of pneumonia increased depending on the dose of inhaled steroid, a recent meta-analysis failed to demonstrate such a relation (24). If evaluated based on this probability, the present study found no relation between ICS use and pneumonia.

\section{CONCLUSION}

The probability of having a non-pneumonic exacerbation is higher than the probability of pneumonic exacerbation as the severity of chronic obstructive pulmonary disease increases. The prevalence of non-pneumonic exacerbation was found to be higher in COPD patients that had a longer disease duration, higher rates of smoking, and more severe disease.

Informed Consent: Written informed consent was obtained from patients who participated in this study. 
Peer-review: Externally peer-reviewed.

Author contributions: Concept - M.H.Ö., S.D.; Design - M.H.Ö., S.D.; Supervision - M.H.Ö.; Resource - S.D.; Data Collection\&/or Processing - S.D.; Analysis\&/ or Interpretation - M.H.Ö, S.D.; Literature Search - S.D.; Writing - S.D.; Critical Reviews - M.H.Ö.

Conflict of Interest: No conflict of interest was declared by the authors.

Financial Disclosure: The authors declared that this study has received no financial support.

\section{REFERENCES}

1. Vestbo J, Hurd SS, Rodriguez-Roisin R. The 2011 revision of the global strategy for the diagnosis, management and prevention of COPD (GOLD) - why and what? Clin Respir J 2012; 6: 208-14. [CrossRef]

2. Mathers $C D$, Loncar $D$. Projections of global mortality and burden of disease from 2002 to 2030. PLoS Med 2006; 3: e442. [CrossRef]

3. Loddenkemper R, Gibson GJ, Sibille Y.The burden of lung disease in Europe: why a European white book on lung disease? Eur Respir J 2003; 22: 869. [CrossRef]

4. Ornek T, Tor M, Altın R, Atalay F, Geredeli E, Soylu O, et al. Clinical factors affecting the direct cost of patients hospitalized with acute exacerbation of chronic obstructive pulmonary disease. Int J Med Sci 2012; 9: 285-90. [CrossRef]

5. Donaldson GC, Seemungal TA, Bhowmik A, Wedzicha JA. Relationship between exacerbation frequency and lung function decline in chronic obstructive pulmonary disease. Thorax 2002; 57: 847-52. [CrossRef]

6. Ling SH, van Eeden SF. Particulate matter air pollution exposure: role in the development and exacerbation of chronic obstructive pulmonary disease. Int J Chron Obstruct Pulmon Dis 2009; 4: 233-43. [CrossRef]

7. Sethi S, Murphy TF. Infection in the pathogenesis and course of chronic obstructive pulmonary disease. N Engl J Med 2008; 359: 2355-65. [CrossRef]

8. Sethi S, Wrona C, Grant BJ, Murphy TF. Strain-specific immune response to haemophilus influenzae in chronic obstructive pulmonary disease. Am J Respir Crit Care Med 2004; 169: 448-53. [CrossRef]

9. Wouters EF. The burden of COPD in the netherlands: results from the confronting COPD survey. Respir Med 2003; 97: 51-59. [CrossRef]

10. Dev D, Wallace E, Sankaran R, Cunniffe J, Govan JR, Wathen CG, et al. Value of $C$ - reactive protein measurements in exacerbations of chronic obstructive pulmonary disease. Respir Med 1998; 92: 664-7. [CrossRef]

11. Hurst JR, Vestbo J, Anzueto A, Locantore N, Müllerova H, Tal-Singer R, et al. Susceptibility to exacerbation in chronic obstructive pulmonary disease. N Engl J Med 2010; 363: 1128-38. [CrossRef]
12. Pujades-Rodríguez $M$, McKeever $T$, Lewis $S$, Whyatt $D$, Britton J, Venn A. Effect of traffic pollution on respiratory and allergic disease in adults: cross-sectional and longitudinal analyses. BMC Pulm Med 2009; 9: 42. [CrossRef]

13. Chabot F, Gomez E, Guillaumot A, Kheir A, Chaouat A. Acute exacerbations of chronic obstructive pulmonary disease. Presse Med 2009; 38: 485-95. [CrossRef]

14. Barnes PJ, Celli BR. Systemic manifestations and comorbidities of COPD. Eur Respir J 2009; 33: 1165-85. [CrossRef]

15. Spranger J, Kroke A, Mohlig M, Hoffmann K, Bergmann MM, Ristow M, et al. Inflammatory cytokines and the risk to develop type 2 diabetes: results of the prospective population-based European prospective investigation into cancer and nutrition (EPIC)-Potsdam Study. Diabetes 2003; 52: 812-7. [CrossRef]

16. Mirrakhimov AE. Chronic obstructive pulmonary disease and glucose metabolism: a bitter sweet symphony. Cardiovascular Diabetol 2012; 11: 132. [CrossRef]

17. Rosenberg SR, Kalhan R. Biomarkers in chronic obstructive pulmonary disease. Transl Res 2012; 159: 228-37. [CrossRef]

18. Sparrow D, Glynn RJ, Cohen M, Weiss ST. The relationship of the peripheral leukocyte count and cigarette smoking to pulmonary function among adult men. Chest 1984; 86: 383-6. [CrossRef]

19. Lazovic B. Correlation of CRP and serum level of fibrinogen with severity of disease in chronic obstructive pulmonary disease patients. Med Arh 2012; 66: 159-60. [CrossRef]

20. Garcia-Rio F, Miravitlles M, Soriano JB, Mu-oz L, Duran-Tauleria E, Sánchez $\mathrm{G}$, et al. Systemic inflammation in chronic obstructive pulmonary disease: a population-based study. Respir Res 2010; 11: 63. [CrossRef]

21. Man SF, Connett JE, Anthonisen NR, Wise RA, Tashkin DP, Sin DD. C-reactive protein and mortality in mild to moderate chronic obstructive pulmonary disease. Thorax 2006; 61: 849-53. [CrossRef]

22. Lieberman $D$, Gelfer $Y$, Varshavsky R, Dvoskin B, Leinonen $M$, Friedman MG. Pneumonic vs nonpneumonic acute exacerbations of COPD. Chest 2002; 122: 1264-70. [CrossRef]

23. Dev D, Wallace E, Sankaran R, Cunniffe J, Govan JR, Wathen CG, et al. Value of $\mathrm{C}$-reactive protein measurements in exacerbations of chronic obstructive pulmonary disease. Respir Med 1998; 92: 664-7. [CrossRef]

24. Sin DD, Tashkin D, Zhang $X$, Radner F, Sjöbring $U$, Thorén $A$, et al. Budesonide and risk of pneumonia: a meta-analysis of individual patient data. Lancet 2009; 374: 712-9. [CrossRef] 